\title{
International Perspectives on Integrated Employment
}

For at least the last 20 years, there has been a movement to bolster the adoption of policies and strategies that lead to integrated employment for people with significant disabilities in the United States [1]. Advocates, service innovators, and government leaders have often joined together to promote the concept that employment is possible and desirable for all people, regardless of the nature of the disability or the need for support in finding and keeping jobs in the workplaces of private and public sector employers [2]. In other words, the notion of presumed employability is advancing due to people with disabilities wanting to work in integrated jobs, strategies that have evolved to make this possible, and legislative and policy developments that support it.

To varying degrees, many other countries have pursued the ideal of presumed employability. They are closely watching this movement in the U.S. and other countries so as to learn from the evolution of these activities as they each endeavor to adopt policies and practices that promote integrated employment for people with disabilities. This special issue of the Journal of Vocational Rehabilitation includes selected articles from scholars and practitioners from around the world who offer their perspectives on the integrated employment movement in the context of their respective countries' history, culture, language, and governments. These diverse ideas, viewpoints, practices, and legislative activities offer useful insights across international boundaries, especially as strategies to promote the employment of people with significant disabilities become more refined and as integrated employment becomes more broadly accepted and practiced.
For the purposes of this issue, and consistent with the definition used by the U.S. Department of Labor, Office of Disability Employment Policy (ODEP), integrated employment refers to jobs held by people with significant disabilities in typical workplace settings where the majority of persons employed are not persons with disabilities, where they earn a commensurate wage but not less than the minimum wage, and where they are paid directly by the employer [3]. It is fitting, then, that Kathleen Martinez, the ODEP Assistant Secretary, lead off with the first article in this issue. As she discusses, the U.S. has made important advances and has a number of initiatives underway to promote integrated employment. As she also discusses, there is still much to be done to make the practice more universal.

International perspectives in this issue are offered from five continents. Assistant Secretary Martinez offers a U.S. perspective. Authors from Japan, Brazil, Portugal, Argentina, and Australia present viewpoints and circumstances that characterize implementation of integrated employment initiatives in their countries. All of these countries have laws and policies that support employment access for individuals with disabilities. Some provide incentives to employers to hire people with disabilities. Others have mandated that both private and public employers meet specific hiring quotas. Some have anti-discrimination laws, others have strong regulations requiring not just non-discrimination but also affirmative efforts to boost the presence of people with disabilities in the workplace. Some have evolving policy structures and funding mechanisms to promote and support the growth and quality of integrated employment so that all people, including 
those with the most significant disabilities, have greater employment access. Others are only just beginning to go down that path. All admit to having a long way to go before integrated employment is the norm.

I invite you to reflect on their similarities, differences, and, most of all, the universal promise they represent to expand extant knowledge of integrated employment policy and practice. There is much to be gained from ongoing international exchange among advocates, practitioners, and researchers who are involved in activities that will show how, when and under what circumstances people with significant disabilities experience successful employment.

\section{Guest Editor}

Richard G. Luecking, Ed.D

TransCen, Inc.

401N. Washington Street, Suite 450

Rockville, MD 20850, USA

E-mail: rluecking@transcen.org

\section{References}

[1] Wehman, P. Employment for persons with disabilities: Where are we now and where do we need to go? Journal of Vocational Rehabilitation. 2011; 35: 145-151.

[2] Martinez, K. Integrated employment, employment first, and U.S. Federal policy. Journal of Vocational Rehabilitation. 2013; 39: 165-168.

[3] Office of Disability Employment Policy, U. S. Department of Labor. Integrated Employment. 2012. Available from: http:// www.dol.gov/odep/topics/IntegratedEmployment.htm 